Although upper body musculoskeletal disorders (MSDs) represent an increasingly important issue for university students, few if any studies have targeted the occupational therapy faculty. Given this dearth of information, it was considered necessary to investigate a cross-section of Australian occupational therapy students by means of an established questionnaire survey. Completed replies were obtained from $95.7 \%, 100 \%$ and $97.7 \%(n=44,55$ and 48$)$ of students in the first, second and fourth years of a large occupational therapy school in northern Queensland, Australia.

The 12-month period prevalence of MSDs was as follows: neck $(67.4 \%)$, shoulder $(46.3 \%)$ and upper back (39.5\%). Three-quarters of all students $\mathbf{7 5 . 5 \% )}$ reported an MSD occurring in at least one of these body regions. Over half $(56.5 \%)$ reported an MSD over 2 days' duration in the past year. Almost $40 \%(39.5 \%)$ reported an MSD that had affected their daily life, while one-quarter $(25.2 \%)$ needed some type of treatment.

Logistic regression indicated that students aged over 21 years were almost four times more likely to report shoulder-related MSD (OR 3.7, 95\% Cl: 1.4-10.2). Year of study in the occupational therapy course was another important MSD correlate, with adjusted odds ratios ranging from 3.3 at the upper back (OR 3.3, 95\% Cl: 1.2-9.6) to 10.9 at the neck (OR 10.9, 95\% Cl: 3.2-43.8). Computer usage also incurred a certain degree of risk, with students who spent over 5 hours per week on the computer having an increased risk of MSD at the neck (OR 5.0, 95\% Cl: 1.3-21.5) and shoulder (OR 4.7, 95\% Cl: 1.4-18.3).

Overall, this study suggests that Australian occupational therapy students have a large burden from MSDs in the upper body region, even more so than other student groups and some working populations. Since the distribution of MSD risk is not uniform among them, interventions to help reduce these conditions need to be carefully targeted. Further longitudinal investigations would also be useful in determining the mechanisms and contributory factors for MSDs among this unique student population.

\title{
Upper Body Musculoskeletal Disorders among Australian Occupational Therapy Students
}

\author{
Derek R Smith, Peter A Leggat and Michele Clark
}

\section{Introduction}

There are currently around 12,000 occupational therapists in Australia, representing approximately $10 \%$ of the allied health workforce. The student population is also significant, with 2472 undergraduates in 2004, and the profession itself is expected to grow by $7 \%$ to $12 \%$ per annum (Occupational Therapy Australia 2005). Although the exact size of the international workforce is not known, there are at least 35,000 occupational therapists, assistants and students in the United States (American Occupational Therapy Association 2005) and there are currently around 28,000 members of the British Association / College of Occupational Therapists (2005).
Despite the fact that occupational therapists are responsible for a large proportion of skilled health care worldwide, occupational health issues among them have rarely been studied. Similarly, although occupational therapy student numbers are constantly increasing in Australia, few if any research projects have investigated unique health issues among them. This is particularly surprising because contemporary research suggests that upper body musculoskeletal disorders (MSDs), in particular, represent an important burden for university students in the health science faculties (Smith and Leggat 2004, Rising et al 2005, Smith et al 2005) and elsewhere (Katz et al 2000, Hupert et al 2004, Hamilton et al 2005). 
Given this dearth of information, it was considered necessary to conduct a detailed epidemiological investigation of upper body MSDs among Australian occupational therapy students, with a particular focus on MSD sequelae and associated risk factors. An additional benefit from this research would be to establish a baseline level of MSDs among occupational therapists before they entered the workforce and were subsequently exposed to the pressures of full-time employment. To the researchers' knowledge, such investigations had not previously been conducted in Australia, if anywhere.

Self-reporting surveys are a cost-effective method for collecting MSD data from large groups and their validity and accuracy have been demonstrated in various studies (Holmström and Moritz 1991, Ohlsson et al 1994, Baron et al 1996, Björkstén et al 1999, Kaergaard et al 2000). The usefulness and convenience of MSD questionnaires have also been shown among university students in a variety of countries (Katz et al 2000, Smith et al 2003, Hupert et al 2004, Smith and Leggat 2004, Hamilton et al 2005, Rising et al 2005, Smith et al 2005). Considering these factors, it was decided to investigate upper body MSDs among a cross-section of Australian occupational therapy students by means of a standardised MSD questionnaire (Kuorinka et al 1987).

\section{Method}

\section{Participants}

The participants recruited to this study were all undergraduate occupational therapy students currently enrolled at a large regional university in northern Queensland, Australia. Although there were four consecutive grades, the third-year students could not be accessed because they were away from campus undergoing practice placements. Owing to the large geographical area of northern Queensland, these students were widely dispersed and could not be contacted readily. It was also considered unethical to contact them individually (by post) and, as such, the third-year group had to be excluded. Of the students currently on campus, 46,55 and 49 were available from the first, second and fourth years of the course respectively. All were considered eligible and were thus enrolled in the study.

\section{Questionnaire design and administration}

The study protocol was reviewed and approved by a university human ethics committee in 2004. The research design and methodology followed ethical standards appropriate for human research in Australia. Epidemiological data on occupational therapy students' MSDs were gathered by means of an anonymous self-reporting questionnaire. The survey itself was a simple two-page form, based predominantly on the Standardised Nordic Questionnaire for the Analysis of Musculoskeletal Symptoms (Kuorinka et al 1987), as well as questions used in other MSD investigations conducted among university students in various countries (Katz et al 2000,
Smith et al 2003, Hupert et al 2004, Smith and Leggat 2004, Hamilton et al 2005, Rising et al 2005, Smith et al 2005). It comprised a simple tick-box format, with the first section covering demographic items such as age, gender, tobacco smoking, alcohol consumption, year of study in the occupational therapy course, whether they had any children, the type of exercise they usually undertook (if any) and, finally, the presence of a family history of injuries (arthritis, slipped discs, ligament damage or carpal tunnel syndrome). Two additional questions included a five-way scale ( $<6$ hours, 6-10 hours, 11-15 hours, 16-20 hours and >20 hours) to establish the usual duration of time spent on a computer every week and also the amount of time spent doing desk work per week (independent of the computer).

The MSD questions included a simple anatomical diagram, which focused on the occurrence of symptoms in the neck, shoulder and upper back regions during the previous 12-month period. The term 'musculoskeletal disorders' referred to any ache, pain or discomfort in the defined body region, as originally described by Kuorinka et al (1987). The validity and reliability of the Nordic Questionnaire have been previously addressed by Baron et al (1996), who found it to be acceptable in these regards. As such, this methodology was considered appropriate for a study of occupational therapy students. Clearly labelled arrows indicated specifically shaded regions on the diagram, corresponding to the three different body sites. Additional MSD-related questions asked about the duration of symptoms, whether they affected the student's daily life and whether treatment had been sought for the condition. A 12-month recall period was used throughout, because this had been shown to be an appropriate time-scale in previous student investigations (Smith et al 2003, Smith and Leggat 2004, Smith et al 2005)

Questionnaires were distributed at the end of a prearranged lecture, following a short introduction conducted by the researchers where the purpose of the study was carefully explained. There were no penalties or rewards for participation and informed consent was implied if students voluntarily completed and returned their questionnaires. This methodology was considered appropriate for two main reasons. First, given the time constraints placed upon the study by the limited availability of occupational therapy students, distributing the questionnaire during lecture times was considered to be the most practical method for obtaining a satisfactory response rate. Second, a brief introduction to the study was deemed appropriate for students (particularly the first-year group), who might be unfamiliar with completing questionnaire-based MSD surveys. It also allowed a clear explanation of ethical principles and a reinforcement of the voluntary nature of the study.

\section{Statistical analysis}

The data were entered into a spreadsheet programme and analysed by statistical software. Demographic items were 
stratified by year of study, with statistically significant differences between the years evaluated using the chi-square test (for discrete variables) and one-way analysis of variance (for continuous variables). Prevalence rates for MSD were calculated as percentages for each subgroup, with statistically significant differences between the genders evaluated using the chi-square test (for variables with cell counts over five) and Fisher's exact test (for variables with cell counts of five or under).

Logistic regression analysis was also performed to determine possible correlations between MSD and various other factors (such as demographic items, sporting activity, computer usage and desk work). The results were calculated as a ratio between the expected rate and the actual rate of MSD, with a value of 1.0 indicating no increased or decreased risk (Bland and Altman 2000). The analysis of correlates for each body site (neck, shoulder, upper back or any MSD) was conducted simultaneously and further adjusted for alcohol consumption, tobacco smoking, parenthood, weekly exercise and family history of injuries. The output from statistical analysis was subsequently expressed as adjusted Odds Ratios (OR), with $95 \%$ confidence intervals $(95 \% \mathrm{CI})$. Probability values below 0.05 were regarded as statistically significant during all tests.

\section{Results}

\section{Demographic items}

Completed questionnaires were received from 44, 55 and 48 students in the first, second and fourth years, giving response rates of $95.7 \%, 100 \%$ and $97.7 \%$ respectively. Their average age ranged from 20.0 years in the first-year group to 22.0 years in the fourth-year group. The majority were female (with the percentage of females in each year ranging from $81.8 \%$ to $89.6 \%$ ).

Alcohol consumption was reasonably common, with between $50.0 \%$ and $72.9 \%$ of students reporting occasional drinking. This rate varied significantly between the years of study ( $p=0.0488)$. Tobacco smoking was very rare, however, being reported by only $2.3 \%$ to $4.2 \%$. By type of activity, the percentage of students in each year who reported that they undertook regular physical exercise was as follows: team sports (21.8\% to $34.1 \%)$, personal training ( $16.7 \%$ to $22.7 \%$ ), jogging ( $25.0 \%$ to $37.5 \%)$ and 'other' ( $47.9 \%$ to $56.8 \%$ ) (see Table 1 ).

Almost one-third of students (31\%) spent 6 to 10 hours per week doing computer work (see Fig. 1). The time spent doing computer work varied significantly between students in different years of study in the occupational therapy course $(p=0.0028)$. Desk work was also reported at high rates, with $38 \%$ of all students undertaking 6 to 10 hours of this activity per week (see Fig. 2).

Of those with a family history of injury, arthritis was the most common subcategory, with between $34.6 \%$ and $39.6 \%$ of students having a family member with this
Table 1. Demographic items and response rate of occupational therapy students

First year $^{\mathrm{a}}$ Second year ${ }^{\mathrm{a}}$ Fourth year ${ }^{\mathrm{a}} \mathrm{p}$ value $^{\mathrm{b}}$

\begin{tabular}{|c|c|}
\hline \multicolumn{2}{|l|}{ Demographics } \\
\hline Age $( \pm S D)^{c} \ldots \ldots \ldots$ & $\ldots 20.0 \pm 4.1 \ldots \ldots .21 .0 \pm 4.5 \ldots \ldots \ldots .22 .0 \pm 2.6 \ldots \ldots .0 .0614 \ldots$ \\
\hline emale .............. & $\ldots 81.8 \ldots \ldots \ldots \ldots .89 .1 \ldots \ldots \ldots \ldots \ldots . .89 .6 \ldots \ldots \ldots .0 .4613 \ldots$ \\
\hline Alcohol .................. & 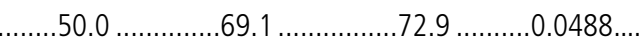 \\
\hline Tobacco ........... & $\ldots \ldots .4 .2 \ldots \ldots \ldots . .8757 \ldots$ \\
\hline \multicolumn{2}{|l|}{ Exercise } \\
\hline Team sports ...... & $.034 .1 \ldots \ldots \ldots \ldots . .21 .8 \ldots \ldots \ldots \ldots \ldots .29 .2 \ldots \ldots \ldots .0 .3890 \ldots$ \\
\hline Personal training. & $\ldots 16.7 \ldots \ldots \ldots .0 .7447 \ldots$ \\
\hline Jogging ... & $\ldots 25.0 \ldots \ldots \ldots \ldots . .30 .9 \ldots \ldots$ \\
\hline Other .................. & $\ldots .56 .8 \ldots \ldots \ldots \ldots .54 .6 \ldots \ldots \ldots \ldots \ldots . .47 .9 \ldots \ldots \ldots .0 .6676 \ldots$ \\
\hline urvey respon & $\ldots 95.7 \ldots \ldots \ldots \ldots . . .100 .0 \ldots$. \\
\hline
\end{tabular}

a Percentage of students in each year ( $n=44,55$ and 48 respectively).

b Significant differences between year of study established using the chi-square test ( $p$ for trend) and one-way analysis of variance (ANOVA).

c Average age of students in each year of study (SD = standard deviation).

d Survey response rate per year of study.

Fig. 1. Hours usually spent per week undertaking computer work. *

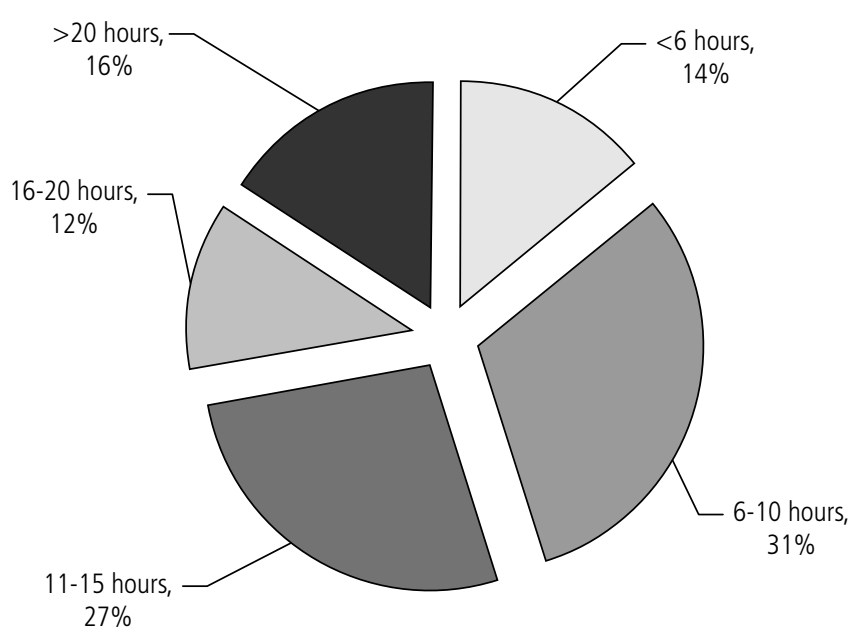

* Significant difference in prevalence rates between year of study in the occupational therapy course $(p=0.0028)$.

Fig. 2. Hours usually spent per week undertaking desk work.

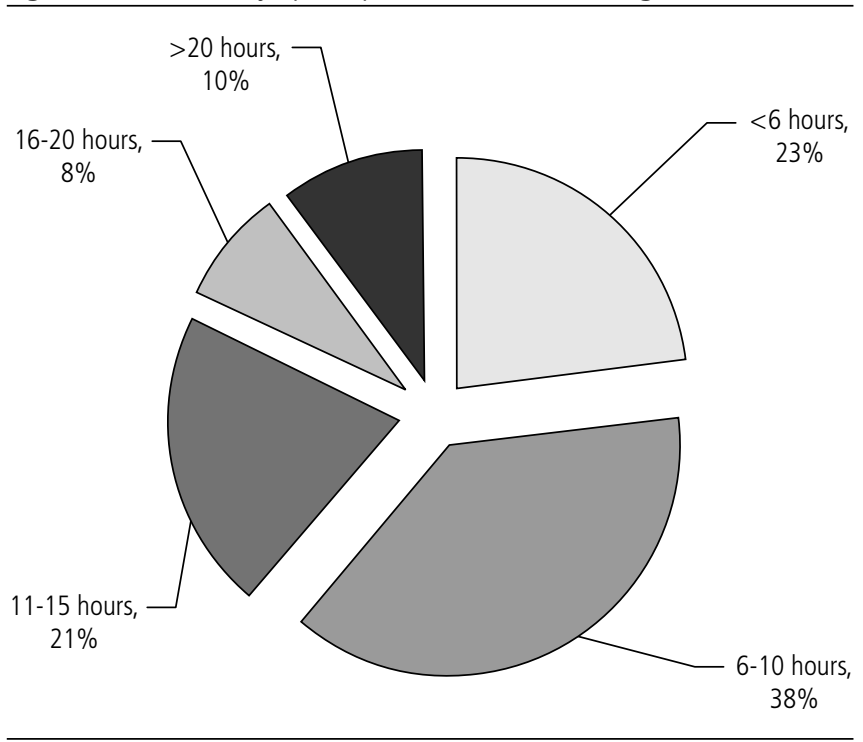


condition. A family history of slipped discs was reported by between $10.4 \%$ and $11.4 \%$ of students, ligament damage affected between $6.3 \%$ and $11.4 \%$ of their family members and carpal tunnel syndrome occurred in between $1.8 \%$ and $18.8 \%$ of their family members. The prevalence of the last condition varied significantly between students in different years of study in the occupational therapy course $(p=0.0173)$ (see Fig. 3 ).

Fig. 3. Family history of injuries among Australian occupational therapy students.

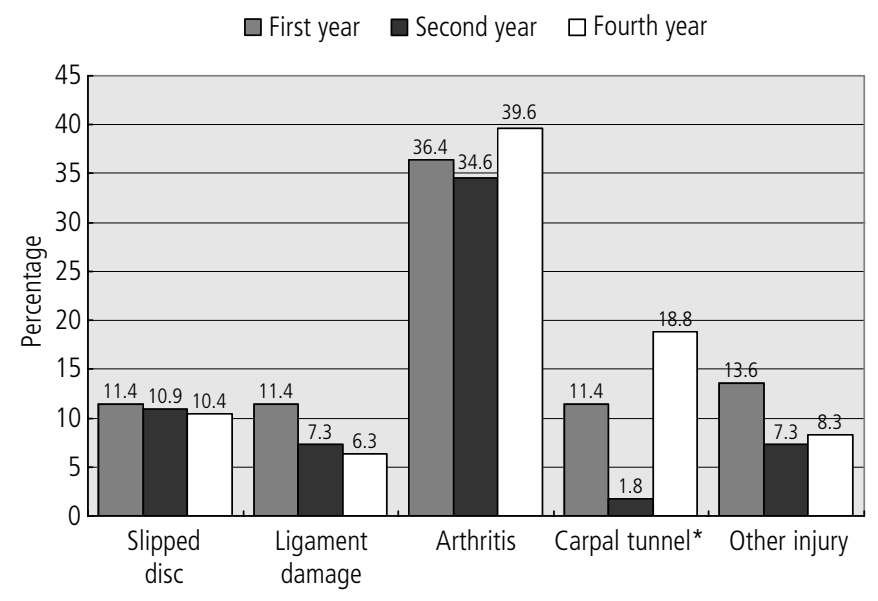

* Significant difference in prevalence rates between year of study in the occupational therapy course $(p=0.0173)$.

\section{Prevalence of MSDs}

The 12-month period prevalence of MSDs at the individual body regions was as follows: neck (67.4\%), shoulder (46.3\%) and upper back (39.5\%). Three-quarters of all students (75.5\%) reported an MSD occurring in at least one of these body regions. By gender, females reported a significantly higher level of neck disorders (70.3\%) when compared with males (47.4\%) ( $p=0.0466)$ No statistically significant differences in prevalence were found at the other body sites, however (shoulder, M 57.9\% vs F 44.5\%; upper back, M 42.1\% vs F $39.1 \%$; and any site, M 73.7\% vs F 75.8\%). MSD episodes persisted longer than 2 days at the neck (44.9\%), shoulder (33.3\%) and upper back (29.9\%), with over half (56.5\%) of all students having had an MSD over 2 days' duration in the past year. Almost 40\% (39.5\%) had an MSD that had affected their daily life, while one-quarter (25.2\%) needed some type of treatment. None of these results showed statistically significant differences by gender (see Table 2).

The distribution of MSDs and their related sequelae varied significantly by year of study in the occupational therapy course. The prevalence of any MSD ranged from $59.1 \%$ to $89.6 \%(p=0.0031)$ and the prevalence of MSD symptoms persisting over 2 days ranged from $38.6 \%$ to $70.8 \%$ ( $p=0.0075)$. MSDs affecting the students' daily life ranged from $32.7 \%$ to $52.1 \%$ and the prevalence of MSDs requiring treatment ranged from $22.7 \%$ to $27.1 \%$ (see Fig. 4).
Table 2. Prevalence of musculoskeletal disorders by gender

\begin{tabular}{|c|c|c|c|}
\hline & Male $^{a}$ & Female $^{a}$ & All b \\
\hline \multicolumn{4}{|l|}{$\overline{\text { Neck }}$} \\
\hline Any symptoms*... & $\ldots .47 .4 \ldots$ & $\ldots .70 .3 \ldots$. & $\ldots 67.4 \ldots$ \\
\hline Persisted $>2$ days. & ....26.3. & $\ldots .47 .7 \ldots$ & $\ldots 44.9 \ldots$ \\
\hline Affected daily life ... & ....15.8. & $\ldots .27 .3 \ldots$ & $\ldots 25.9 \ldots$ \\
\hline Needed treatment.. & $\ldots .10 .5 \ldots$ & .....18.0 ..... & $\ldots 17.0 \ldots \ldots$ \\
\hline \multicolumn{4}{|l|}{ Shoulder } \\
\hline Any symptoms......... & ....57.9 ... & $\ldots .44 .5 \ldots .$. & $\ldots 46.3 \ldots \ldots$ \\
\hline Persisted $>2$ days. & ....31.6 ... & .....33.6 ..... & ...33.3......... \\
\hline Affected daily life ... & $\ldots .15 .8 \ldots$ & $\ldots .22 .7 \ldots \ldots$ & $\ldots 21.8 \ldots \ldots$ \\
\hline Needed treatment.. & ......5.3. & $\ldots .14 .1 \ldots$. & $\ldots 12.9 \ldots \ldots$ \\
\hline \multicolumn{4}{|l|}{ Upper back } \\
\hline Any symptoms......... & $\ldots .42 .1 \ldots$ & .....39.1 ..... & ...39.5......... \\
\hline Persisted $>2$ days. & $\ldots .26 .3 \ldots$ & $\ldots .30 .5 \ldots$. &. $.29 .9 \ldots \ldots$ \\
\hline Affected daily life ... & $\ldots .10 .5 \ldots$ & $\ldots .19 .5 \ldots$ & $\ldots 18.4 \ldots$ \\
\hline Needed treatment.. & ....5.3 ... & $\ldots . .11 .7 \ldots .$. & $\ldots 10.9 \ldots \ldots$ \\
\hline \multicolumn{4}{|l|}{ Any regionc } \\
\hline Any symptoms......... & $\ldots .73 .7 \ldots$ & $\ldots .75 .8 \ldots .$. &. $.75 .5 \ldots \ldots$ \\
\hline Persisted $>2$ days. & ....52.6 ... & .....57.0 ..... & $\ldots 56.5 \ldots \ldots$ \\
\hline Affected daily life ... & $\ldots .26 .3 \ldots$ & $\ldots .41 .4 \ldots .$. & ...39.5 ......... \\
\hline Needed treatment.. & $\ldots .15 .8 \ldots$ & $\ldots . .26 .6 \ldots .$. &. $.25 .2 \ldots$ \\
\hline
\end{tabular}

a Percentage of students in each subcategory.

b Statistically significant differences between the genders evaluated using the chi-square test and Fisher's exact test ( ${ }^{*} p=0.0466$ ).

' Either neck, shoulder or upper back musculoskeletal disorders.

Fig. 4. Prevalence of musculoskeletal disorders by year of study.

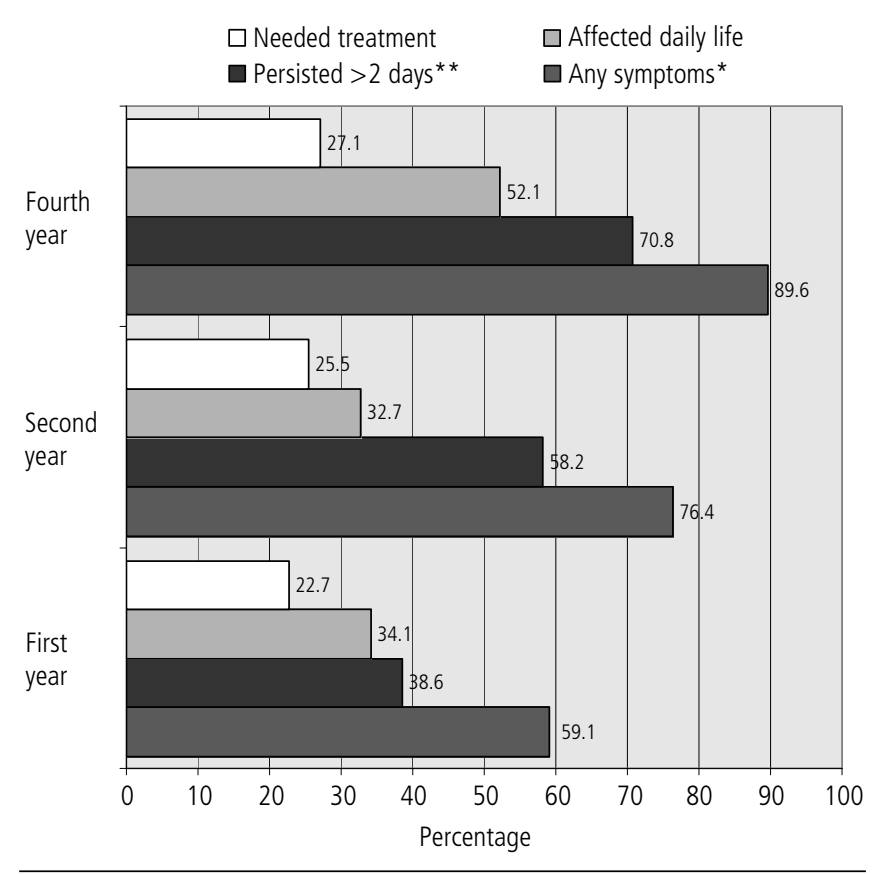

Significant differences in prevalence rates between year of study in the occupational therapy course $\left({ }^{*} p=0.0031,{ }^{* *} p=0.0075\right)$.

\section{Statistical correlations with MSDs}

Logistic regression analysis indicated that age, year of study and weekly computer usage were statistically significant risk factors for MSDs. After adjustment for confounding variables, students aged over 21 years were almost four times more likely to report a shoulder-related 
Table 3. Statistical correlations with upper body musculoskeletal disorders among Australian occupational therapy students

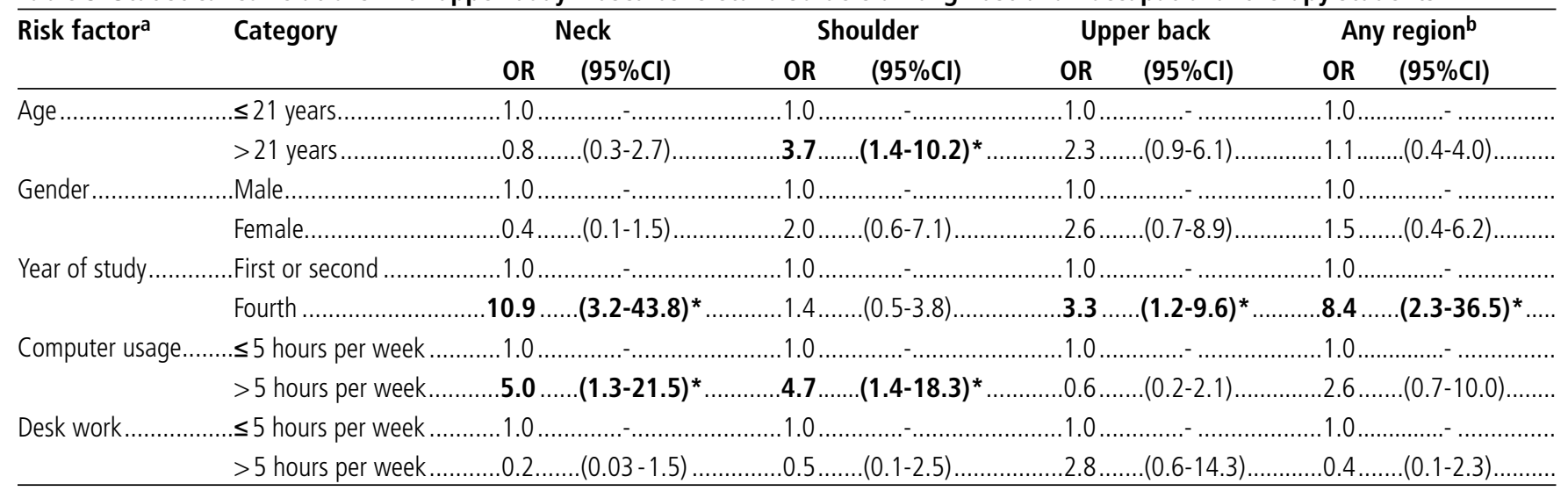

a Risk factors calculated simultaneously and expressed as adjusted Odds Ratios (OR) with 95\% Confidence Intervals (95\%Cl), adjusted for alcohol consumption, tobacco smoking, parenthood, weekly exercise and family history of injuries ( $\left.{ }^{*} p<0.05\right)$.

b Either neck, shoulder or upper back musculoskeletal disorders.

MSD than their classmates who were 21 years of age or younger (OR 3.7, 95\%CI: 1.4-10.2).

Year of study in the occupational therapy course was another important correlate for MSDs. In this regard, fourth-year students were 3.3 times more likely to report an MSD at the upper back (OR 3.3, 95\%CI: 1.2-9.6), 8.4 times more likely to report an MSD at any region (OR 8.4, 95\%CI: 2.3-36.5) and 10.9 times more likely to report an MSD of the neck (OR 10.9, 95\%CI: 3.2-43.8) when compared with students in the other grades.

Computer usage also incurred a certain degree of risk, with students who spent over 5 hours per week on the computer incurring an increased risk of an MSD at the shoulder (OR 4.7, 95\%CI: 1.4-18.3) and the neck

(OR 5.0, 95\%CI: 1.3-21.5) (see Table 3).

A family history of arthritis was correlated with the presence of an upper back MSD (OR 2.4, 95\%CI: 1.1-5.5) (data not shown). No other statistically significant results were observed during logistic regression analysis.

\section{Discussion}

\section{MSD prevalence rates}

MSDs were most commonly reported in the neck region during this study, affecting over two-thirds (67.4\%) of all occupational therapy students in the previous year. This result was higher than previous investigations conducted among nursing students in Korea (35.6\%) (Smith et al 2005), Australia (34.6\%) (Smith and Leggat 2004) and Japan (9.5\%) (Smith et al 2003), as well as the rate of neck-shoulder disorders in an American dental school (Rising et al 2005) (29\% to $58 \%$ ). Previous research also seems to indicate lower prevalence rates among hospital nurses in the United States (45.8\%) (Trinkoff et al 2002) and Sweden (48\%) (Lagerström et al 1995). Regarding the general community, Lau et al (1996) found that the one-year prevalence of neck pain may be around $15 \%$ in men and $17 \%$ in women.

Slightly less than half the occupational therapy students in the present study (46.3\%) reported an MSD in the shoulder region over the past year, which is similar to a recent nursing student investigation from Korea (46.0\%) (Smith et al 2005). Both are higher than other research projects undertaken among nursing students in Australia (23.8\%) (Smith and Leggat 2004) and Japan (14.9\%) (Smith et al 2003). The prevalence of upper back MSDs among Australian occupational therapy students was also higher than another nursing student investigation conducted in Korea, where it affected $18.8 \%$ of the participants (Smith et al 2005).

Differences in MSD prevalence rates between the occupational therapy students in this study and those of other student investigations are difficult to explain conclusively. Nevertheless, it has previously been suggested that inter-student differences in health-promoting behaviour may occur within universities of the same country. Najem et al (1995), for example, conducted a multifaculty study in the same university and found that medical students exercised more frequently than dental students or nursing students. Coe et al (1982) documented how medical students undertook health-promoting behaviour more regularly than law students at the same university. Kamwendo (2000) also showed that Swedish occupational therapy students, in particular, were more physically active and smoked less than nursing students. It is possible, therefore, that differences in health-promoting behaviour may exist between university students in different specialties and in different universities. Such differences might be particularly marked if compared internationally.

Crosscultural differences in self-reporting behaviour may also exist between university students in Asia and those of Western countries. When considering previous research conducted among Asian nursing students (Smith et al 2003, 2005), the issue of Confucianism is important, because there may be a tendency for these students to under-report MSD symptoms. If so, self-assessed perceptions of pain (during questionnaire surveys) may vary between different ethnic groups and will, therefore, need to be investigated with more extensive crosscultural research. The development of a standardised, international 
MSD questionnaire for university students may be useful in this regard. It might not be a panacea, however, and would need to be tested and validated across a variety of countries and different cultures, as well as among different study majors, such as occupational therapy, medicine, dentistry and nursing.

\section{Correlations with year of study}

By simple chi-square analysis ( $p$ for trend), there were statistically significant differences in overall MSD prevalence rates by year of study in the occupational therapy course, with fourth-year students having the highest rates. This correlation also remained when evaluated in a combined regression model, which would have accounted for interactions between MSDs and confounding demographic variables (such as increasing age with increasing year of study). Indeed, the logistic regression model also demonstrated that being a fourth-year student was a risk factor for MSDs of the neck and upper back. Interestingly, these correlations between MSDs and year of study in the occupational therapy course were contrary to previous investigations of Korean (Smith et al 2005) and Japanese (Smith et al 2003) nursing students, where no such relationships were found.

Fourth-year students may incur an increased MSD risk due to their occupational therapy practice placements, when compared with students in the other years of study. If so, it is possible that third-year students who are undertaking practice placements for the first time may be at even higher MSD risk, although for practical reasons, as mentioned in the method section, it was not possible to survey them during the present study.

It is also possible that as they progress through the course, occupational therapy students learn more about MSDs and simply become more attuned to MSD symptoms. On the other hand, the significantly higher percentage of fourth-year students whose MSD symptoms persisted longer than 2 days suggests the possibility of some genuine organic conditions, which will need to be studied in future research projects.

\section{Correlations with gender}

The investigation of MSDs and their correlation with demographic items produced some interesting results. By simple chi-square analysis, there were statistically significant differences in MSD prevalence at the neck region, with females reporting higher rates. This finding was consistent with previous research from the United States (Hupert et al 2004). The higher rate of shoulder MSD reported by females in the investigation by Hupert et al (2004) was not evidenced during the present study, because the male occupational therapy students actually reported slightly higher (although non-statistically significant) prevalence rates. Either way, the results of the present investigation and those conducted in various countries suggest that relationships between MSDs and gender are not straightforward among student cohorts. For example, Katz et al's (2000) research suggested that females might experience an elevated risk for MSDs of the upper body. Among dental students, however, Rising et al (2005) demonstrated that although a higher proportion of females reported neck/shoulder pain than males, this difference was not statistically significant. In the same study, Rising et al (2005) also found that, overall, a higher proportion of male dental students reported pain in the mid to lower back regions when compared with their female counterparts. On the other hand, research conducted among Australian nursing students suggested a significantly higher rate of shoulder MSDs for males (Smith and Leggat 2004).

Although these conflicting results make it difficult to ascertain whether gender actually represents a true MSD risk factor or not, the present results at least indicate possible relationships between female gender and MSD development among Australian occupational therapy students. It may be hypothesised that males have a higher background level of physically demanding sporting activities. If this were the case, it is conceivable that the lower proportion of male occupational therapy students in the present study was simply not sufficient to reveal any differences at a statistically significant level. On the other hand, differences in MSD prevalence rates may also relate to gender preferences in leisure-time activities, study habits, personal demographics or a combination of these issues. Again, future longitudinal research will be needed among student cohorts to help to elucidate the exact contributory factors.

\section{Computer usage as a significant risk factor}

The identification of computer usage as a significant MSD risk factor in the neck and shoulder region was another important finding. Computer-related MSDs have previously been shown to be problematic for students in a variety of studies from the United States (Katz et al 2000, Hupert et al 2004, Hamilton et al 2005). In a study of office workers, Blatter and Bongers (2002) showed that using a computer more than 6 hours per day was associated with an MSD of the neck or upper limbs, a finding that is similar to the present results. Although the students' posture while using a computer was not measured in the present study, Szeto et al (2002) suggested that poor neck and shoulder postures may be a cause of MSDs among computer operators. Linton (1990) found a similar relationship between neck pain and uncomfortable work posture among Swedish employees. In a review of occupational risk factors for shoulder pain, van der Windt et al (2000) also confirmed this fact.

The exact type of computer used may be another issue, because Hamilton et al (2005) documented how 90\% of students who used a laptop computer later reported musculoskeletal discomfort. Psychosocial factors are also worth considering when investigating MSDs, because an increasing body of evidence has begun to reveal clear relationships in this regard (Linton and Kamwendo 1989, Bongers et al 1993, Lagerström et al 1995, Bongers et al 2002, Smith et al 2004). There is also the possibility that the timing of the study (towards the end of the year) 
simply coincided with a period of increased computer usage among students. As such, future studies of MSDs among university students should take these additional factors into account.

\section{Lack of relationship with previously established risk factors}

Not all previously established risk factors were evident during the present study. Lau et al (1996), for example, conducted an MSD study among the general community and found that participants with neck pain spent significantly more time reading than those without symptoms. Despite this fact, the category of desk work (which included reading but not computer usage) was not related to an MSD at any body site during the present study. Regular exercise was not associated with a reduced MSD risk during this study, which is contrary to a previous investigation of American university students where participation in athletics seemed to offer a protective effect against MSD of the upper body (Katz et al 2000). A similar result has also been reported among Korean nursing students (Smith et al 2005), although it is difficult to ascertain whether exercise actually reduces the risk of MSD or whether those students with MSDs would simply be unable to undertake any regular sporting activity.

MSD was not associated with parenthood during the current investigation, which is contrary to a previous study conducted by Finkelstein (1995), although the latter did not focus on students. A similar comment may also be appropriate for smoking because no relationship between tobacco use and MSDs was elucidated in the present study, a result that is, again, contrary to that reported by some other authors (Lincoln et al 2003). The complicity of parenthood and smoking in MSD development would, therefore, still appear to be under debate, and thus remains an important topic in need of further research.

\section{Future research}

Although this study of MSDs among occupational therapy students was reasonably thorough, further investigations may be helpful, particularly if conducted longitudinally both before and after graduation. This type of future study would help to establish how, why and if MSD rates change after an occupational therapy student begins full-time employment. The possible links between various risk factors and MSDs should also be investigated in this regard, again, through the use of longitudinal research and follow-up studies. As mentioned earlier in the discussion, the development of an internationally standardised MSD questionnaire for students in all faculties would be very useful for such investigations.

\section{Conclusion}

Overall, this study suggests that Australian occupational therapy students have a large burden from MSDs in the upper body region, even more so than other student groups and some working populations. Further investigations will now be required to elucidate the mechanisms and contributory factors for MSDs among this unique student population. A longitudinal study among a complete group of occupational therapy students would be very useful for such investigations.

\section{Acknowledgements}

We are grateful to all students who completed our questionnaire and to staff from the Occupational Therapy Unit, James Cook University, Townsville, for their organisational support. Thanks are also due to Dr Frances Leggat for her assistance in data coding and entry.

\section{References}

American Occupational Therapy Association (2005) About AOTA. Available at: http://www.aota.org/general/about.asp Accessed on 07.11.05.

Baron S, Hales T, Hurrell J (1996) Evaluation of symptom surveys for occupational musculoskeletal disorders. American Journal of Industrial Medicine, 29, 609-17.

Björkstén MG, Boquist B, Talbäck M, Edling C (1999) The validity of reported musculoskeletal problems. A study of questionnaire answers in relation to diagnosed disorders and perception of pain. Applied Ergonomics, 30, 325-30.

Bland JM, Altman DG (2000) The odds ratio. British Medical Journal, 320, 1468. Blatter BM, Bongers PM (2002) Duration of computer use and mouse use in relation to musculoskeletal disorders of neck or upper limb. International Journal of Industrial Ergonomics, 30, 295-306.

Bongers PM, de Winter CR, Kompier MAJ, Hildebrandt VH (1993) Psychosocial factors at work and musculoskeletal disease. Scandinavian Journal of Work, Environment and Health, 19, 297-312. Bongers PM, Kremer AM, ter Laak J (2002) Are psychosocial factors, risk factors for symptoms and signs of the shoulder, elbow, or hand/wrist?: A review of the epidemiological literature. American Journal of Industrial Medicine, 41, 315-42.

British Association/College of Occupational Therapists (2005). How can OT help me? Available at: http://www.cot.org.uk/newpublic/otandme/ intro.php Accessed on 07.11.05.

Coe RM, Miller DK, Wolff M, Prendergast JM, Pepper M (1982) Attitudes and health promoting behavior of medical and law students. American Journal of Public Health, 72, 725-27.

Finkelstein MM (1995) Back pain and parenthood. Occupational and Environmental Medicine, 52, 51-53.

Hamilton AG, Jacobs K, Orsmond G (2005) The prevalence of computer-related musculoskeletal complaints in female college students. Work, 24, 387-94.

Holmström E, Moritz U (1991) Low back pain - correspondence between questionnaire, interview and clinical examination. Scandinavian Journal of Rehabilitation Medicine, 23, 119-25.

Hupert N, Amick BC, Fossel AH, Coley CM, Robertson MM, Katz JN (2004) Upper extremity musculoskeletal symptoms and functional impairment associated with computer use among college students. Work, 23, 85-93.

Kaergaard A, Andersen JH, Rasmussen K, Mikkelsen S (2000) Identification of neck-shoulder disorders in a 1 year follow-up study. Validation of a questionnaire-based method. Pain, 86, 305-10.

Kamwendo K (2000) Adherence to healthy lifestyles: a comparison of occupational therapy students with nursing and physiotherapy students. Scandinavian Journal of Occupational Therapy, 7, 156-64. 
Katz JN, Amick BC, Carroll BB, Hollis C, Fossel AH, Coley CM (2000) Prevalence of upper extremity musculoskeletal disorders in college students. American Journal of Medicine, 109, 586-88.

Kuorinka I, Jonsson B, Killbom A, Vinterberg H, Biering-Sørensen F, Andersson G, Jørgensen $K$ (1987) Standardised Nordic questionnaires for the analysis of musculoskeletal symptoms. Applied Ergonomics, 18, 233-37.

Lagerström M, Wenemark M, Hagberg M, Hjelm EW, The Moses Study Group (1995) Occupational and individual factors related to musculoskeletal symptoms in five body regions among Swedish nursing personnel. International Archives of Occupational and Environmental Health, 68, 27-35.

Lau EMC, Sham A, Wong KC (1996) The prevalence of and risk factors for neck pain in Hong Kong Chinese. Journal of Public Health Medicine, 18, 396-99.

Lincoln AE, Smith GS, Amoroso PJ, Bell NS (2003) The effect of cigarette smoking on musculoskeletal-related disability. American Journal of Industrial Medicine, 43, 337-49.

Linton SJ (1990) Risk factors for neck and back pain in a working population in Sweden. Work and Stress, 4, 41-49.

Linton SJ, Kamwendo K (1989) Risk factors in the psychosocial work environment for neck and shoulder pain in secretaries. Journal of Occupational Medicine, 31, 609-13.

Najem GR, Passannante MRC, Foster JD (1995) Health risk factors and health promoting behavior of medical, dental and nursing students. Journal of Clinical Epidemiology, 48, 841-49.

Ohlsson K, Attewell RG, Johnsson B, Ahlm A, Skerfving S (1994) An assessment of neck and upper extremity disorders by questionnaire and clinical examination. Ergonomics, 37, 891-97.

OT Australia (2005) About occupational therapy. Available at: http://www.ausot.com.aulinner.asp?pageid=85 Accessed on 07.11.05.

Rising DW, Bennett BC, Hursh K, Plesh 0 (2005) Reports of body pain in a dental student population. Journal of the American Dental Association, $136,81-86$.

Smith DR, Leggat PA (2004) Musculoskeletal disorders among rural Australian nursing students. Australian Journal of Rural Health, 12, 241-45.
Smith DR, Sato M, Miyajima T, Mizutani T, Yamagata Z (2003)

Musculoskeletal disorders self-reported by female nursing students in central Japan: a complete cross-sectional survey. International Journal of Nursing Studies, 40, 725-29.

Smith DR, Wei N, Zhao L, Wang RS (2004) Musculoskeletal complaints and psychosocial risk factors among Chinese hospital nurses. Occupational Medicine, 54, 579-82.

Smith DR, Choe MA, Chae YR, Jeong JS, Jeon MY, An GJ (2005) Musculoskeletal symptoms among Korean nursing students. Contemporary Nurse, 19, 151-60.

Szeto GPY, Straker L, Raine S (2002) A field comparison of neck and shoulder postures in symptomatic and asymptomatic office workers. Applied Ergonomics, 33, 75-84.

Trinkoff AM, Lipscomb JA, Geiger-Brown J, Brady B (2002) Musculoskeletal problems of the neck, shoulder and back and functional consequences in nurses. American Journal of Industrial Medicine, 41, 170-78.

van der Windt, DAWM, Thomas E, Pope DP, de Winter AF, Macfarlane GJ, Bouter LM, Silman AJ (2000) Occupational risk factors for shoulder pain: a systematic review. Occupational and Environmental Medicine, 57, 433-42.

\section{Authors}

Derek R Smith, BSc, MHSc, MPH, PhD, DrMedSc, Research Scientist, International Centre for Research Promotion and Informatics, Japan National Institute of Occupational Safety and Health, 6-21-1 Nagao, Tama-ku, Kawasaki 214-8585 Japan, and Visiting Senior Research Fellow, School of Public Health, Tropical Medicine and Rehabilitation Sciences, James Cook University, Townsville, Australia. Email: smith@niih.go.jp

Peter A Leggat, BMedSc, MBBS, MMedEd, MPH, MHSc, PhD, MD, DrPH, Associate Professor, School of Public Health, Tropical Medicine and Rehabilitation Sciences, James Cook University, Townsville, Australia.

Michele Clark, BOccThy(Hons), BA, PhD, Professor, School of Public Health, Tropical Medicine and Rehabilitation Sciences, James Cook University, Townsville, Australia. 